\title{
Driving and emergency braking may be impaired after tibiotalar joint arthrodesis: conclusions after a case series
}

\author{
Stefan Schwienbacher ${ }^{1}$ - Emin Aghayev ${ }^{2}$ - Ulf Krister Hofmann ${ }^{3}$ - Maurice Jordan ${ }^{3}$. \\ Antongiulio Marmotti ${ }^{4} \cdot$ Christoph Röder $^{2} \cdot$ Ingmar Ipach $^{5}$
}

Received: 21 March 2015 / Accepted: 4 April 2015 / Published online: 7 May 2015

(C) SICOT aisbl 2015

\begin{abstract}
Purpose To assess whether reaction time (RT) and movement time (MT), as the two components of the total brake response time (TBRT) and brake force (BF) are different in patients with a foot joint arthrodesis in comparison to controls.

Methods The study was a comparative case series in a driving simulator under realistic driving conditions. Mobile patients without a walker, $\geq 6$ months after surgery who were driving a car and had no neurological co-morbidity, knee or hip joint prosthesis were included in the study. The selection criteria resulted in 12 patients with right tibiotalar joint arthrodesis (TTJA) and 12 patients with another right foot joint arthrodesis (OFJA), who were compared to 17 individuals without any ankle-joint pathology. For TBRT, an empirical safe driving threshold of $700 \mathrm{~ms}$ was used. The outcome measures were RT, MT, TBRT, BF and McGuire score.
\end{abstract}

$\overline{\text { Study design and setting Comparative case series in a driving simulator }}$ under realistic driving conditions

$\overline{\text { Stefan Schwienbacher and Emin Aghayev contributed equally to this }}$ work

Stefan Schwienbacher

sschwienbacher84@googlemail.com

1 Department of Orthopaedic Surgery and Traumatology, Inselspital, University of Bern, Freiburgstrasse 4, 3010 Bern, Switzerland

2 Institute for Evaluative Research in Medicine, University of Bern, Stauffacherstrasse 78, 3014 Bern, Switzerland

3 Department of Orthopaedic Surgery, University Hospital of Tübingen, Hoppe-Seyler-Strasse 3, 72076 Tübingen, Germany

4 Department of Orthopaedics and Traumatology, Mauriziano Hospital, University of Torino, Largo Turati 62, 10128 Turin, Italy

5 Department of Orthopaedic Surgery, Klinikum Ingolstadt, Krumenauerstraße 25, 85049 Ingolstadt, Germany
Results MT $(p=0.034)$ and TBRT $(p=0.026)$ were longer in TTJA patients in comparison with the controls. Also, more patients with TTJA than patients with OFJA and controls exceeded the safe driving threshold $(p=0.028)$. The outcomes in OFJA patients and in controls were comparable. The McGuire score was similar between the TTJA and OFJA patients $(p=0.26)$.

Conclusions Significantly slower MT and TBRT, and significantly more patients exceeding the safe driving threshold, were observed after a tibiotalar-joint arthrodesis in comparison to the controls. Patients with OFJAs were not significantly different from the controls. Driving and emergency braking may be impaired after tibiotalar-joint arthrodesis.

Keywords Foot joint arthrodesis $\cdot$ Car driving $\cdot$ Total brake response time $\cdot$ Reaction time, Movement time $\cdot$ Brake force $\cdot$ McGuire score · Tibiotalar joint

$\begin{array}{ll}\text { Abbreviations } \\ \text { RT } & \text { reaction time } \\ \text { MT } & \text { movement time } \\ \text { TBRT } & \text { total brake response time } \\ \text { BF } & \text { brake force } \\ \text { TTJA } & \text { tibiotalar joint arthrodesis } \\ \text { OFJA } & \text { other foot joint arthrodesis }\end{array}$

\section{Introduction}

One of the most common questions asked by patients undergoing an arthrodesis of the tibiotalar or talocalcaneal joint is whether the arthrodesis affects the ability to drive a car. Various abilities are required for safe car driving. An important measure is the ability of emergency braking for an emergency 
stop. The time required for an emergency braking is referred to as total brake response time (TBRT) [1-3]. TBRT is the sum of the reaction time (RT), movement time (MT) and device response time, according to Green [4] (Table 1).

The braking distance is mostly determined by the car velocity, but it also depends on the car weight, brake properties, and the properties of the road surface. Over the past years successful technical efforts have been made to reduce braking distance. The last challenge remaining is the reaction distance, however. At a speed of $60 \mathrm{~km} / \mathrm{h}$ the reaction distance is longer than the braking distance of the car itself [5].

A lower-limb-joint replacement or an arthrodesis may potentially influence the TBRT. The annual numbers of ankle joint arthrodeses performed, as well as the number of hospitals that perform this kind of surgery, are gradually growing according to the only published German data [6]. Trauma is the most frequent indication for a foot joint arthrodesis, making up $49 \%$ of all arthrodeses captured in the German Orthopaedic Foot and Ankle Association's registry [6].

Several studies have analysed TBRT and braking force (BF) after total knee and total hip replacement [3, 7-9]. To our knowledge, only one study is known to examine the TBRT following ankle joint arthrodesis. The study showed that TBRT following a healed right ankle arthrodesis in ten patients was significantly lower than that of ten healthy controls, whereas the BF did not significantly differ between the patients and the controls [10]. However, this age-matched study did not distinguish between different arthrodesis types. The study also did not adjust for patient sex, which might hypothetically have an influence on the reaction and movement times and/or on braking force.

The purpose of the current study was (1) to compare the RT, MT, TBRT and braking force (BF) between patients with different arthrodesis types and healthy controls adjusted for patient age and sex and (2) to measure the proportion of patients with a too slow TBRT.

\section{Materials and methods}

The study was approved by the local ethics committee. Informed consent was received from every patient and control.

\section{Patients and controls}

The selection criteria for this study were mobile patients without a walker, at a minimum of six months after a right foot joint arthrodesis, who were driving a car at least once a week and had no neurological co-morbidity, motor deficits or a score of less than $4 / 5$ according to the British Medical Research Council Scale, infection, artificial knee or hip joint or drug intake with a known influence on the reaction time. All consecutive patients who received a foot joint arthrodesis between February 2006 and October 2012 at our department were invited and agreed to participate in the study. The sample included 12 patients who underwent a right tibiotalar joint arthrodesis (TTJA group) and 12 patients who received another foot joint arthrodesis (OFJA group). More specifically, the OFJA group consisted of six patients with a talonavicular arthrodesis, two patients with a subtalar arthrodesis, two patients with a talocalcaneal arthrodesis, one patient with a triple arthrodesis and one patient with a calcaneocuboidal arthrodesis. A third group of 17 healthy volunteers without any ankle pathology was assessed as controls. All participants were regularly driving a car, at least once a week, having a valid driving license.

\section{Outcome measures}

The outcome measures were TBRT, RT, MT, BF and McGuire score. Additionally, the proportion of patients with the TBRT above $700 \mathrm{~ms}$ was assessed.

\section{Simulator}

In consideration of the spatial constraints in a real car cabin, a brake simulator was built based on a Volkswagen car model (Fig. 1a). Force transducers from Megatron ${ }^{\circledR}$ Electronics were mounted to the acceleration and brake pedals to assess the outcome measures (Fig. 1c). Measured time intervals and applied forces were displayed on the computer screen as a diagram after each testing (Fig. 1d). For the assurance of the accuracy of the BF measurements, a calibration of the sensor was conducted for each testing based on a standard procedure.

Table 1 Components of Total Brake Response Time according to Green [4]

\begin{tabular}{lll}
\hline 1. Reaction time & 2. Movement time & 3. Device response time \\
- Sensation & - Lift the foot off the accelerator pedal and transfer it to the brake & - Time it takes the devise to engage once activate \\
- Perception/recognition & - Depress the pedal \\
- Situational awareness & \\
- Response selection & \\
- Programming & \\
\hline
\end{tabular}


Fig. 1 The car cabin and brake simulator
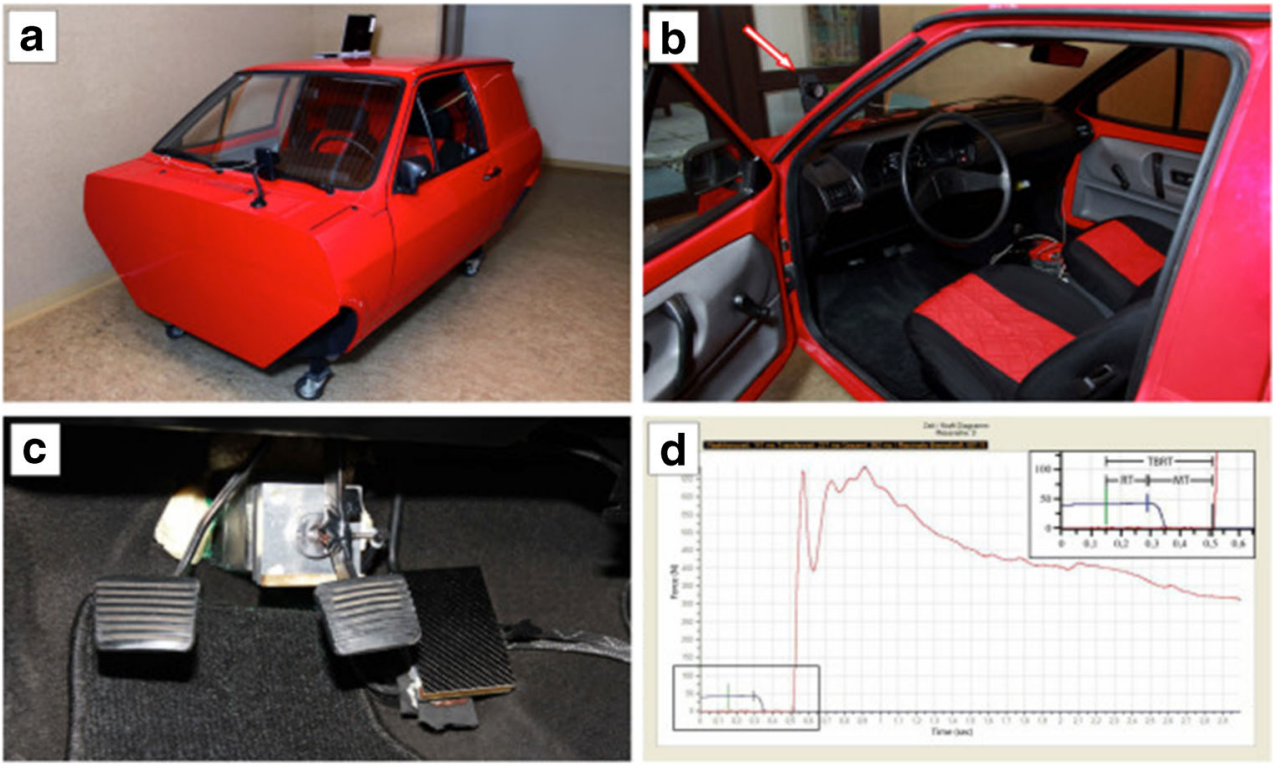

\section{Measurement}

Participants were asked to wear convenient footwear that they typically wear during driving. The seat was adjusted in distance and tilt to be convenient for the driving position of each participant. Standardised instructions about the usage of the brake simulator were given prior to testing. Some time for a test run was also provided. Depression of the accelerator pedal activated the computer-based registration. Participants were instructed to keep the pedal permanently depressed with their right foot until a red light flashed up. The light was mounted to the front lid (arrow in Fig. 1b). The light signal was representing an emergency and causing the participant to initiate an emergency braking. In doing so the right foot of the participant should be lifted off the accelerator pedal and transferred to the brake pedal to apply the maximum brake force. Within a period of ten seconds after the participant had positioned himself or herself, the supervisor activated the light signal randomly by an external trigger which was not visible to the participants. The interval between the activation of the light signal and the start of the decrease of the force measured on the accelerator pedal was determined as the reaction time. MT was defined as the interval between the start of force decrease on the accelerator and the start of the force application to the brake pedal. The combination of the two times resulted in the TBRT. In parallel, the force applied to the brake pedal was measured.

For the evaluation of functional status in both treatment groups a patient-based McGuire score was used. The score was first described in 1988 and is known as a simple clinical measure of function for patients with a foot joint arthrodesis [11]. The score includes dimensions of pain, walking distance, support, walking on uneven surfaces, range of motion, climbing stairs and limping with three to five answer options.
The score values are read as follows: $80-100$, excellent; 70 79 , good; 65-69, poor; $<65$, failed.

\section{Statistical analyses}

After a test run, the outcome measures of the ten following repeated trials were averaged and the average value was used in the analysis.

Categorical variables are presented as frequencies and percentages, and continuous variables as means with standard deviations and medians with ranges.

Differences between all three groups in outcome measures were evaluated using the generalised linear modelling with pairwise comparisons adjusted for patient age and sex. Bonferroni correction was used to adjust for multiple testing. In addition, the proportion of participants above the empirical TBRT threshold of $700 \mathrm{~ms}$ according to the U.S. Federal Highway Administration $[10,12]$ was compared between the groups using Fisher's exact test.

All statistical analyses were conducted using SAS 9.4 (SAS Institute, Cary, NC) with an $\alpha=0.05$.

\section{Results}

In the OFJA, TTJA and control groups the mean ages were 55 \pm 17 years (median 62 and range $22-73$ years), $59 \pm 15$ years (median 58 and range 24-76 years) and $66 \pm 10$ years (median 65 and range $50-84$ years) (overall $p=0.08$ ), respectively. The proportion of female patients was $58.3 \%, 50.0 \%$ and $17.7 \%$ in the respective groups $(p=0.055)$.

The results of outcome measures are shown in Table 2. The mean measured times were the lowest in the control group, followed by OFJA and TTJA patients. The mean measured 

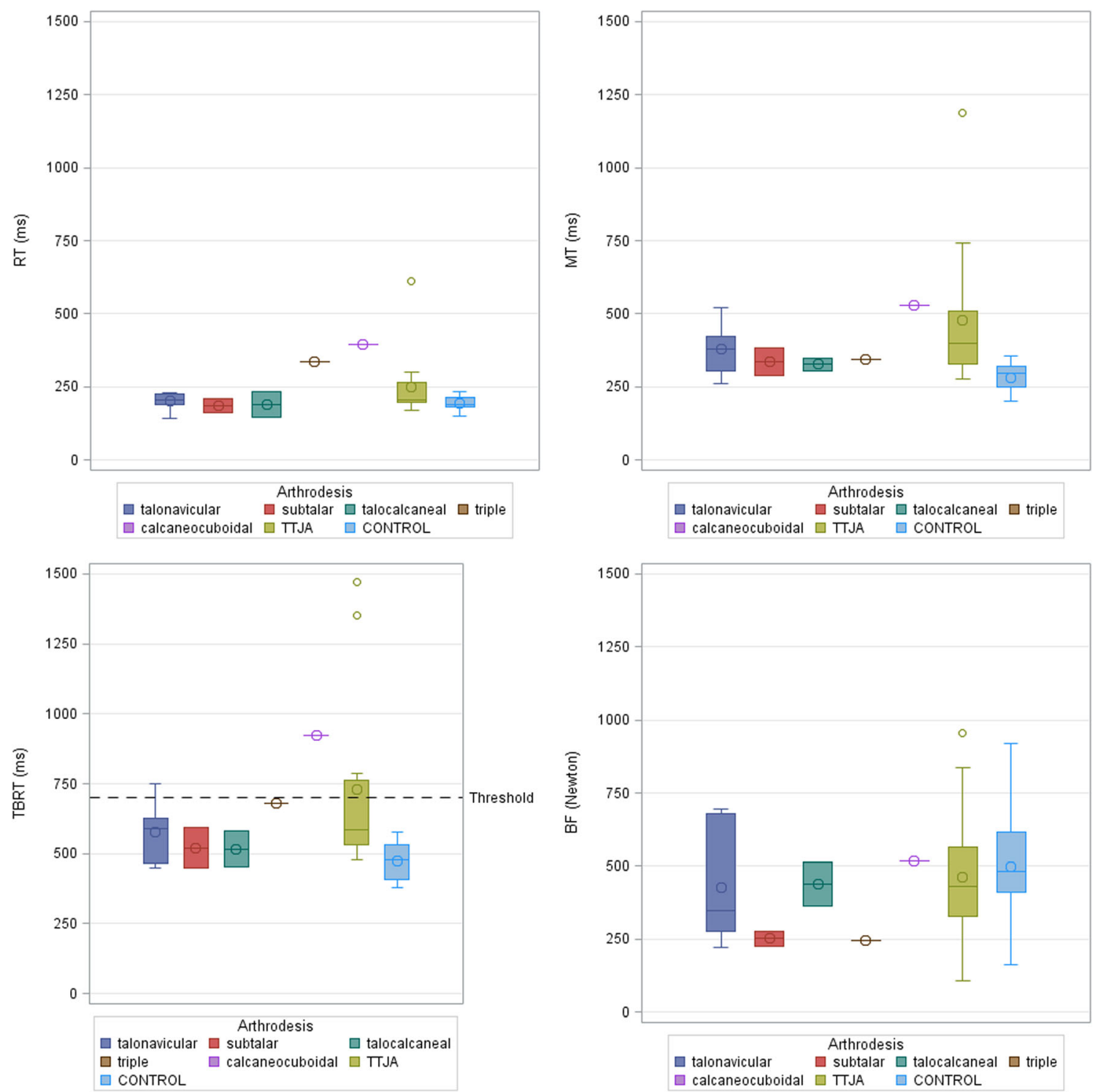

Fig. 2 Results for the individual arthrodesis subgroups and controls

BF was the highest in the control group followed by TTJA and OFJA patients. RT and BF did not differ significantly between the three groups $(p>0.28)$. MT as a component of TBRT and TBRT itself in TTJA patients were both significantly higher than in the controls (Table 2; $p=0.034$ and $p=0.026$, respectively).

The mean McGuire score was 83.2 \pm 12.4 (median 78.5, range 49-96) and $76.6 \pm 15.6$ (median 88 , range 54-99) in OFJA and TTJA patients, respectively $(p=0.26)$.

None of the controls, two patients with OFJA (16.7\%) and four patients with TTJA (33.3 \%) had the mean TBRT exceeding the threshold of $700 \mathrm{~ms}(p=0.028)$ up to two times. In the control group, 9 out of the 170 individual measurements $(5.3 \%)$ in the 17 volunteers only marginally exceeded the threshold.

The results of the individual arthrodesis subgroups and controls are displayed in Fig. 2 as boxplots.

\section{Discussion}

The question, "Can I drive a car?", concerns a major part of patients undergoing a foot joint arthrodesis. Clinical experience shows that patients undergoing a foot joint arthrodesis care more about their functional outcome and the ability to drive a car after surgery than about the surgery itself. The braking process is a complex combination of plantar flexion and dorsal extension in the ankle, rotation in the hip and extension in the knee. A foot joint arthrodesis may, therefore, potentially affect the driving ability, much like knee and hip surgeries.

Spalding et al. [3] were the first to report on reaction time after total knee replacement. Their study on 40 patients showed that a reasonable driving ability is achieved eight weeks after surgery. Marques et al. [1] showed that driving ability with a safe brake response time after a total knee 
Table 2 RT, MT, TBRT and BF in the study groups

\begin{tabular}{|c|c|c|c|c|c|c|c|c|}
\hline Outcome & $\begin{array}{l}\text { Study } \\
\text { group }\end{array}$ & $\mathrm{N}$ & Mean & SD & Median & Range & $\begin{array}{l}\text { Comparison vs } \\
\text { controls } \\
\text { (p-value) }\end{array}$ & $\begin{array}{l}\text { Comparison vs } \\
\text { UAJA } \\
\text { (p-value) }\end{array}$ \\
\hline \multirow[t]{3}{*}{ RT } & OFJA & 12 & 223.8 & 74.0 & 208.0 & $143.9-395.5$ & 1.0 & 1.0 \\
\hline & TTJA & 12 & 250.2 & 120.3 & 204.8 & $170.8-611.8$ & 0.28 & - \\
\hline & Control & 17 & 193.3 & 24.3 & 188.7 & $151.3-232.4$ & - & - \\
\hline \multirow[t]{3}{*}{ MT } & OFJA & 12 & 372.4 & 85.7 & 357.1 & $259.4-528.1$ & 1.0 & 0.12 \\
\hline & TTJA & 12 & 478.7 & 256.8 & 400.1 & $278.5-1186.5$ & 0.034 & - \\
\hline & Control & 17 & 282.4 & 51.5 & 295.2 & $202.7-354.1$ & - & - \\
\hline \multirow[t]{3}{*}{ TBRT } & OFJA & 12 & 596.2 & 141.4 & 587.1 & $449.7-923.6$ & 1.0 & 0.16 \\
\hline & TTJA & 12 & 729.7 & 332.9 & 585.1 & $478.3-1471.9$ & 0.026 & - \\
\hline & Control & 17 & 475.7 & 63.5 & 477.6 & $378.0-578.4$ & - & - \\
\hline \multirow[t]{3}{*}{$\mathrm{BF}$} & OFJA & 12 & 392.4 & 171.6 & 320.1 & $221.4-696.6$ & 1.0 & 1.0 \\
\hline & TTJA & 12 & 461.1 & 245.8 & 432.2 & $107.5-954.8$ & 1.0 & - \\
\hline & Control & 17 & 499.3 & 169.6 & 482.1 & $162.6-919.1$ & - & - \\
\hline
\end{tabular}

Note: RT - Reaction Time; MT - Movement Time; TBRT - Total Brake Response Time; BF - Braking Force; OFJA - Other Foot Joint Arthrodesis; TTJA - Tibiotalar Joint Arthrodesis; SD - Standard Deviation

replacement is achieved four weeks after surgery. According to the study by Pierson et al. [13], who also studied brake response time after total knee replacement, the driving ability is achieved nine weeks after surgery. Liebensteiner et al. [14] showed that patients with dorsal fusion were able to drive safely after surgery. In another study on the brake response time after complex injuries of the lower extremity, such as acetabulum, calcaneus, tibial plateau and pilon fractures, safe values for this measure were achieved 6 weeks after the initiation of weight-bearing [15].

The studies on driving ability after surgically treated foot joint pathologies are rare. Egol et al. [16] showed that in patients with ankle fractures brake response time reaches the level of healthy controls nine weeks after stabilisation. Holt et al. [2] showed that the brake response time after an osteotomy of the first metatarsal bone for hallux valgus correction was comparable to that of healthy controls six weeks after surgery.

It seems to be reasonable to believe that roughly 2.5 months after a foot joint surgery the ability to drive safely should be restored. Our study addressed this typical patient concern from another perspective, selecting supposedly recovered patients and comparing their total brake response time and other outcome measures to that of the controls and to the threshold proposed by the U.S. Federal Highway Administration [12]. A similar approach was used by Jeng et al. [10], who selected ten patients one year after an ankle arthrodesis surgery, which was not specified, however, and compared them to ten age-matched controls. The author observed a significantly slower TBRT in patients than in controls, whereas BF was not different between the study groups.
Our findings demonstrate that patients with a TTJA were slower in movement and in the overall TBRT in comparison to healthy controls. Although their reaction time and braking force values remained comparable to those of the controls. Considering the small group sizes, one-third $(n=4)$ of the TTJA patients had TBRT exceeding the proposed safety threshold. The parameters RT and BF appear to be of no concern. These results of our TTJA patients are in accordance with the study by Jeng et al. [10].

Our second treatment group of other foot joint arthrodesis showed overall shorter RT, MT and TBRT values than the TTJA patients. Solely, the average BF was slightly lower in OFJA than in TTJA patients. The differences between OFJA and TTJA patients were not significant, however. The numbers of the individual arthrodesis subgroups are too low to allow for a reasonable statistical assessment. However, overall it can be said that the TTJA patients were performing worse than all other arthrodesis subgroups and controls.

The comparable BF in our study groups supports the assumption that the vast majority of braking power is generated in the hip and knee [17].

Different road authorities proposed different TBRT thresholds between $700 \mathrm{~ms}[18,19]$ and 1,500 ms [20]. For our study the lowest proposed threshold of $700 \mathrm{~ms}$, coming from the U.S. road authority, was used. This rather conservative threshold is more appropriate for experimental settings as proposed by Hofmann et al. [21].

The similar reaction time and different movement time points to the affect of the foot kinematics in patients with tibiotalar joint arthrodesis. Movement time was defined as the interval between the start of force decrease on the accelerator and the start of the force application to the brake pedal. 
During acceleration, the forefoot is located on the acceleration pedal and the heel rests on the floor. As Liebensteiner et al. [9] put it, "It is possible to complete the process of braking by flexing the right leg at all major joints and lifting the entire foot from the floor, then adducting the leg towards the brake and again extending the leg. It is also possible to lift just the right forefoot by dorsiflexion of the ankle, adduct the leg at the hip using the heel as a pivot, and then activate the brake by plantar flexion of the foot". In healthy subjects, Scott et al. [22] observed the fastest braking response time in those subjects who solved the task by only moving the foot. Patients with a tibiotalar-joint arthrodesis obviously have affected foot kinematics and are most probably compensating for them by other joints of the lower limb.

Orthopaedic surgeons should be aware of the results of this study as practically every second arthrodesis is performed in a trauma patient [6]. The results of the analysis should be used for the information of the patient and shared decision-making whenever possible. Despite the fact that car driving is an important component of most patients' life and that the number of orthopaedic interventions in the lower limb is constantly growing, no well-established guidelines for determining when it is safe to drive after injury or treatment exist [8]. Based on our findings, it is not reasonable to hold off every patient with a right foot joint arthrodesis from car driving. A standardised assessment of total brake response time in patients six months after a foot joint arthrodesis to ensure his or her safe driving may be a reasonable approach. The creation of such a standard is desirable for warranting inter-patient comparability, which, however, must be left to the respective medical and regulatory expert groups.

This study is of an experimental design. It is unclear how well the results of the simulator reflect the real world driving conditions. However, since a control group was examined and since the TBRT values in all controls was below the used threshold, the achieved comparison results should be valid.

The sample size in this study was low as it was a singlecentre study and as a foot joint arthrodesis is not a frequent surgery in our department. A multi-centric study design may be recommended to increase the sample size, but simulator measurements should still be based on one simulator only, to assure the same standardised approach in all subjects. This might become a logistical challenge. Nevertheless, despite the similar results by Jeng et al. [10] and in our study, the used sample sizes do not allow for definitive conclusions in terms of driving safety after a foot joint arthrodesis. According to the local German Road Authority, all study participants possess a driving license and are hence allowed to drive, which suggests safe driving. The study observed, however, a significantly slower movement time and total brake response time in patients with a tibiotalar joint arthrodesis in comparison to healthy controls. Also, significantly more patients with a tibiotalar joint arthrodesis exceeded the safety driving threshold. The group of other pooled foot joint arthrodesis locations was not significantly different from the controls. Moreover, our study showed a variability of the measured parameters both between individual patients as well as depending on the arthrodesis location. We suggest, therefore, a standardised assessment of total brake response time in patients six months after a foot joint arthrodesis to ensure his or her safe driving.

\section{References}

1. Marques CJ, Barreiros J, Cabri J, Carita AI, Friesecke C, Loehr JF (2008) Does the brake response time of the right leg change after left total knee arthroplasty? A prospective study. Knee 15(4):295298. doi:10.1016/j.knee.2008.02.008

2. Holt G, Kay M, McGrory R, Kumar CS (2008) Emergency brake response time after first metatarsal osteotomy. J Bone Joint Surg Am 90(8):1660-1664. doi:10.2106/JBJS.G.00552

3. Spalding TJ, Kiss J, Kyberd P, Turner-Smith A, Simpson AH (1994) Driver reaction times after total knee replacement. J Bone Joint Surg 76(5):754-756

4. Green M (2000) How long does it take to stop? Methodological analysis of driver perception-brake times. Trans Hum Factors 2000(2):195-216

5. ADAC (2001) Signale 2001. Bereich Verkehrssicherheitsprogramme (VSP), Verkehr und Mathe-Anhalteweg-Fahrphysik. ADAC, München

6. Kostuj T, Preis M, Walther M, Aghayev E, Krummenauer F, Roder C (2014) German Total Ankle Replacement Register of the German Foot and Ankle Society (D.A.F.) - Presentation of design and reliability of the data as well as first results. Z Orthop Unfall 152(5): 446-454. doi:10.1055/s-0034-1382933

7. MacDonald W, Owen JW (1988) The effect of total hip replacement on driving reactions. J Bone Joint Surg 70(2):202-205

8. Marecek GS, Schafer MF (2013) Driving after orthopaedic surgery. J Am Acad Orthop Surg 21(11):696-706. doi:10.5435/JAAOS-21$11-696$

9. Liebensteiner MC, Kern M, Haid C, Kobel C, Niederseer D, Krismer M (2010) Brake response time before and after total knee arthroplasty: a prospective cohort study. BMC Musculoskelet Disord 11:267. doi:10.1186/1471-2474-11-267

10. Jeng CL, Lin JS, Amoyal K, Campbell J, Myerson MS (2011) Driving brake reaction time following right ankle arthrodesis. Foot Ankle Int 32(9):896-899

11. McGuire MR, Kyle RF, Gustilo RB, Premer RF (1988) Comparative analysis of ankle arthroplasty versus ankle arthrodesis. Clin Orthop Relat Res 226:174-181

12. U.S. Department of Transportation (2004) A policy on geometric design of highways and streets. Federal Highway Administration, Washington

13. Pierson JL, Earles DR, Wood K (2003) Brake response time after total knee arthroplasty: when is it safe for patients to drive? J Arthroplasty 18(7):840-843

14. Liebensteiner MC, Birkfellner F, Thaler M, Haid C, Bach C, Krismer M (2010) Driving reaction time before and after primary fusion of the lumbar spine. Spine 35(3):330-335. doi:10.1097/ BRS.0b013e3181b8e11a

15. Egol KA, Sheikhazadeh A, Koval KJ (2008) Braking function after complex lower extremity trauma. J Trauma 65(6):1435-1438. doi: 10.1097/TA.0b013e31811eaab8 
16. Egol KA, Sheikhazadeh A, Mogatederi S, Barnett A, Koval KJ (2003) Lower-extremity function for driving an automobile after operative treatment of ankle fracture. J Bone Joint Surg Am 85A(7):1185-1189

17. Jordan M, Grunwald J, Hofmann U, Meyer M, Sachsenmaier S, Wulker N, Kluba T, Ipach I (2014) The influence of left and right side total hip arthroplasty on the ability to perform an emergency stop while driving a car. Arch Phys Med Rehabil 95(9):1702-1709. doi:10.1016/j.apmr.2014.03.009

18. Department for Transport (1978) The Highway Code. HMSO, London
19. Royal Automobile Club of Victoria (1996) Average reaction, braking and stopping distances in metres at different speeds with reaction time of 0.75 seconds. RACV, Melbourne

20. Burckhardt M (1985) Reaktionszeiten bei Notbremsvorgängen. TÜV Rheinland, Cologne

21. Hofmann UK, Jordan M, Rondak I, Wolf P, Kluba T, Ipach I (2014) Osteoarthritis of the knee or hip significantly impairs driving ability (cross-sectional survey). BMC Musculoskelet Disord 15:20. doi: 10.1186/1471-2474-15-20

22. Scott PA, Candler PD, Li JC (1996) Stature and seat position as factors affecting fractionated response time in motor vehicle drivers. Appl Ergon 27(6):411-416 